УДК 004.93

doi: 10.26906/SUNZ.2019.4.114

Т. М. Шипова, Г. М. Зубрицький, В. В. Кірвас

${ }^{1}$ Національний технічний університет “Харківський політехнічний інститут”, Харків, Україна

${ }^{2}$ Харківський національний університет Повітряних Сил імені Івана Кожедуба, Харків, Україна

\title{
МЕТОД ФОРМУВАННЯ ЕТАЛОННОГО ЗОБРАЖЕННЯ ЯСКРАВОГО ОБ'ЄКТУ
}

\begin{abstract}
У статті розглянуто завдання формування еталонного зображення для об'єкту, у якого на зображеннях можливі суттєві зміни яскравості. Встановлено, що більшість існуючих методів при великих значеннях відношення сигналшум не відповідають вимогам по ймовірності правильного розпізнавання зображення. Метою статті $\epsilon$ розробка методу формування еталонного зображення яскравого об' єкту, заснованого на виборі його оптимального числового представлення, котре в найбільшій мірі відповідає поточному зображенню. Результати досліджень. У представленому методі на кожному етапі порівняння еталонного зображення з фрагментами поточного зображення запропоновано синтезувати оптимальне числове представлення еталонного зображення, що зберігає відношення порядку на його елементах. Для порівняльної оцінки за ймовірністю правильного розпізнавання об'єкта запропонованого і звичайного квадратичного різницевого алгоритмів були проведені статистичні випробування. Висновок. При великих значеннях відношення сигнал-шум запропонований алгоритм істотно перевершує стандартний алгоритм по ймовірності правильного розпізнавання зображення.
\end{abstract}

Ключові слова: еталонне зображення, поточне зображення, яскравість, критерій максимальної правдоподібності, відношення лінійного квазіпорядку.

\section{Вступ}

На сьогодні питання розпізнавання зображень займають дуже важливе місце при розробці різних комп'ютерних систем [1-9]. У багатьох наукових роботах розглядаються різноманітні методи [1-4], при цьому в залежності від параметрів зображення якість розпізнавання може суттєво змінюватися при використанні різних методів. Тому у деяких випадках необхідно вирішення окремих завдань, пов'язаних з особливими характеристиками зображення [5-9]. Зокрема, виникає завдання формування еталонного зображення для об'єкту, у якого на зображеннях можливі суттєві зміни яскравості.

Дане завдання розглядалося у деяких роботах [10-19], але при великих значеннях відношення сигнал-шум запропоновані алгоритми не відповідають вимогам по ймовірності правильного розпізнавання зображення.

Метою цієї статті $є$ розробка методу формування еталонного зображення яскравого об'єкту, заснованого на виборі його оптимального числового представлення, котре в найбільшій мірі відповідає поточному зображенню.

\section{Результати досліджень}

Нехай поточне зображення задано числовою матрицею, що має розмір $N_{1} \times N_{2}$, а еталонне зображення - матрицею $\left[e_{i j}\right]$ розміром $M_{1} \times M_{2}$. Нехай також $є$ вірною адитивна модель взаємодії зображення, що надходить, із шумом, тобто для $(k, l)$-го фрагменту поточного зображення $z_{i j}=a_{i j}+n_{i j}$ де $\left[a_{i j}^{k l}\right]-M_{1} \times M_{2}-$ матриця фрагменту без шуму, $n_{i j}^{k l}$ - випадкова нормально розподілена величина 3 нульовим математичним сподіванням і середньоквадратичним відхиленням (СКВ) $\sigma_{i j}^{k l}$. Оптимальним за критерієм максимальної правдоподібності є при цьому квадратичний різницевий алгоритм, вирішальна функція якого має такий вигляд:

$$
\begin{gathered}
b_{k l}=\sum_{i=1}^{M_{1}} \sum_{j=1}^{M_{2}}\left(z_{i j}^{k l}-e_{i j}\right)^{2} /\left(\sigma_{i j}^{k l}\right)^{2}, \\
k \in \overline{1, N_{1}-M_{1}+1}, \quad l \in \overline{1, N_{2}-M_{2}+1} .
\end{gathered}
$$

Нехай еталонне зображення (Е3) має зонну структуру в кількості $N$ зон із вектором яскравостей $\pi=\left(\pi_{1}, \ldots, \pi_{N}\right)$, на елементах еталонне зображення задано відношення лінійного квазіпорядку [1] або на складових вектора $\pi$ задано відношення лінійного порядку, причому зони пронумеровані в порядку зростання їх яскравостей. Розгорнувши матрицю вирішальної функції, а також Е3 і фрагмент поточного зображення по рядках, представимо вираз (1) у вигляді

$$
b_{k}=c_{k} \sum_{i=1}^{M} p_{i}^{k}\left(z_{i}^{k}-e_{i}\right)^{2},
$$

де

$$
M=M_{1} M_{2} ;
$$

$$
p_{i}^{k}=1 / c_{k}\left(\sigma_{i}^{k}\right)^{2} ; \quad c_{k}=\sum_{i=1}^{M}\left(\sigma_{i}^{k}\right)^{-2} \text {. }
$$

Ввівши $\left[h_{i j}\right],(i \in \overline{1, M}, j \in \overline{1, N})$ - матрицю інцидентності, в якій в $i$-му рядку на $j$-му місці стоїть 1 , якщо $i$-й елемент Е3 належить $j$-й зоні та опустивши множник $c_{k}$ i номер фрагмента, представимо вираз (2) таким чином:

$$
b(\pi)=\sum_{i=1}^{M} p_{i}\left(z_{i}-\sum_{j=1}^{N} h_{i j} \pi_{j}\right)^{2} .
$$


Для пошуку оптимального числового представлення Е3 необхідно мінімізувати функцію (3) при таких обмеженнях:

$$
g_{j}(\pi)=\pi_{j}-\pi_{j+1} \leq 0, \quad j \in \overline{1, N-1} .
$$

Це завдання належить до типу завдань опуклого програмування, для яких справедлива теорема Куна-Таккера [11], яка стверджує наступне: Нехай функції $b, g_{1}, \ldots, g_{N-1}$ опуклі и неперервно диференцуємі в $\mathbf{R}^{N}$ Припустимо, що вектори $\pi \in \mathbf{R}^{N}$ и $\mu \in \mathbf{R}^{N-1}$ задовольняють умовам:

$$
\begin{gathered}
\nabla b(\pi)+\nabla \mathbf{g}(\pi) \mu=0 \\
\mathbf{g}(\pi) \leq 0, \mu \geq 0, \mu_{j} g_{j}(\pi)=0, j \in \overline{1, N-1} .
\end{gathered}
$$

Тоді $\pi \epsilon$ точкою глобального мінімуму задачі, що розглядається.

Система рівнянь (5) та (6) в координатах має такий вигляд:

$$
\left\{\begin{array}{l}
2 n_{1}\left(\pi_{1}-\pi_{1}^{\prime}\right)+\mu_{1}=0 \\
2 n_{2}\left(\pi_{2}-\pi_{2}^{\prime}\right)+\mu_{2}-\mu_{1}=0 \\
\ldots \ldots \ldots \ldots \ldots \ldots \ldots \ldots \ldots \ldots \ldots \ldots \\
2 n_{N-1}\left(\pi_{N-1}-\pi_{N-1}^{\prime}\right)+\mu_{N-1}-\mu_{N-2}=0 \\
2 n_{N}\left(\pi_{N}-\pi_{N}^{\prime}\right)-\mu_{N-1}=0 \\
\mu_{j}\left(\pi_{j}-\pi_{j+1}\right)=0, j \in \overline{1, N-1}
\end{array}\right.
$$

де $n_{i}=\sum_{k \in N_{i}} p_{k}, \pi_{i}^{\prime}=\frac{1}{n_{i}} \sum_{k \in N_{i}} p_{k} y_{k}, N_{i}-$ множина номерів елементів Е3, що попали до $i$-ої зони.

Для вирішення системи (7) будемо використовувати метод послідовного виключення змінних, починаючи $з$ першого рівняння.

У разі відсутності обмежень (за наявності $\mu=0$ ) маємо $\pi=\pi^{\prime}$. Тому на першому етапі перевіримо відношення порядку на елементах $\pi_{1}^{\prime}, \pi_{2}^{\prime}$.

Якщо $\pi_{1}^{\prime}<\pi_{2}^{\prime}$, то і перші два рівняння 3 системи виключаються.

Нехай на $i$-му кроці сталося так, що $\pi_{i}^{\prime} \geq \pi_{i+1}^{\prime}$. Назвемо таку ситуацію блоком інверсій. Щоб виконувалася умова $\pi_{i} \leq \pi_{i+1}$, потрібно покласти $\pi_{i}=\pi_{i+1}$ i $\mu_{i} \geq 0$.

До цього кроку маємо таке:

$$
\begin{gathered}
\mu_{1}=\cdots=\mu_{i}=0, \\
\pi_{k}=\pi_{k}^{\prime}(k \in \overline{1, i-1}) .
\end{gathered}
$$

3 перших двох рівнянь системи знаходимо, що

$$
\mu_{i}=2 n_{i}\left(\pi_{i}^{\prime}-\pi_{i+1}\right)
$$

і маємо рівняння

$$
2 n_{i+1}^{\prime}\left(\pi_{i+1}-\pi_{i+1}^{\prime \prime}\right)+\mu_{i+1}=0,
$$

де $n_{i+1}^{\prime}=n_{i}+n_{i+1}, \pi_{i+1}^{\prime \prime}=\left(n_{i} \pi_{i}^{\prime}+n_{i+1} \pi_{i+1}^{\prime}\right) / n_{i+1}^{\prime}$.

Таким чином, на цьому етапі виключаються змінні $\mu_{i}, \pi_{i}$. Далі, якщо

$$
\pi_{i+1}^{\prime \prime} \geq \pi_{i+2}^{\prime}
$$

то вважаємо

$$
\pi_{i+1} \geq \pi_{i+2}
$$

і знаходимо

$$
\mu_{i+1}=2 n_{i+1}^{\prime}\left(\pi_{i+1}^{\prime \prime}-\pi_{i+2}\right) .
$$

Нехай на $(i+1)$-му кроці виконується умова

$$
\pi_{i+l}^{\prime \prime}<\pi_{i+l+1}^{\prime},
$$

що відповідає закінченню блоку інверсій. Тоді

$$
\begin{aligned}
& \pi_{i+1}=\cdots=\pi_{i+l}=\pi_{i+1}^{\prime \prime}, \\
& \mu_{i+l}=0, \\
& \mu_{i+k}=\frac{2}{n_{i+l}^{\prime}} \sum_{p=i}^{i+k} \sum_{j=i+k+1}^{i+l} n_{p} n_{j}\left(\pi_{p}^{\prime}-\pi_{j}^{\prime}\right), \\
& k \in \overline{0, l-1}, \\
& n_{i+k}^{\prime}=\sum_{j=i}^{i+k} n_{j}, \\
& \pi_{i+k}^{\prime \prime}=\sum_{j=i}^{i+k} n_{j} \pi_{j}^{\prime} / n_{i+k}^{\prime}, k \in \overline{0, l-1} .
\end{aligned}
$$

Продовжуючи подібним чином процес вирішення системи (7) 3 виділенням блоків інверсій, можна вирішити всі рівняння, а з методики її вирішення випливає наведений далі алгоритм вирішення задачі оптимізації.

Крок 1. Задати вектори

$$
\begin{gathered}
\mathbf{p}=\left(p_{1}, \ldots, p_{M}\right), p_{i}>0, \quad \sum_{i=1}^{M} p_{i}=1 ; \\
\mathbf{z} \in \mathbf{R}^{M}, \quad \mathbf{r} \in \overline{1, N}^{M},
\end{gathered}
$$

де компонента $r_{i}$ вектора $\mathbf{r}$ дорівнює номеру зони, якій належить $i$-й елемент Е3.

Крок 2. Побудувати матрицю Н $з$ елементами

$$
h_{i j}=\delta_{r_{i} j}
$$

де $\delta_{i j}$ - символ Кронекера, $i \in \overline{1, M}, j \in \overline{1, N}$.

Крок 3. Побудувати множини

$$
N_{i}=\left\{j \in \overline{1, M}\left(r_{j}=i\right\}, i \in \overline{1, N} .\right.
$$

Крок 4. Побудувати вектори

$$
\begin{gathered}
\mathbf{n} \in \mathbf{R}^{\mathbf{N}}, \quad n_{i}=\sum_{k \in N_{i}} p_{k}, \\
\pi^{\prime} \in \mathbf{R}^{\mathbf{N}}, \quad \pi_{i}^{\prime}=\frac{1}{n_{i}} \sum_{k \in N_{i}} p_{k} z_{k} .
\end{gathered}
$$


Крок 5. Покласти $i=1$.

Крок 6. Покласти

$$
j=1, \quad l=1, \quad s_{1}=\pi_{i}^{\prime} n_{i}, \quad s_{2}=n_{i} .
$$

Крок 7. Якщо $\pi_{j}^{\prime}>\pi_{j+1}^{\prime}$ i $j \leq N-1$, то повторювати таку послідовність:

$$
\begin{gathered}
s_{1}=s_{1}+n_{j+1} \pi_{j+1}^{\prime}, \quad s_{2}=s_{2}+n_{j+1}, \quad \pi_{k}^{\prime}=s_{1} / s_{2}, \\
k \in \overline{j-l+2, j+1}, j:=j+1 .
\end{gathered}
$$

Крок 8. Якщо $i=1$, то покласти $i:=i+1$, інакше покласти $i=j$.

Крок 9. Якщо $i \leq N-1$, то перейти до кроку 6 .

Для порівняльної оцінки за ймовірністю правильного розпізнавання об'єкта запропонованого і звичайного квадратичного різницевого алгоритмів були проведені статистичні випробування. Моделювалося поточне зображення з такими параметрами:

$$
\begin{gathered}
N_{1}=N_{2}=16, \\
T_{2}=250, T_{3}=260,
\end{gathered}
$$

яке потім зашумлять нормально розподіленим шумом 3 нульовим середнім значенням і СКО $\sigma$. Параметри електронного зображення вибиралися такими:

$$
\begin{gathered}
M_{1}=M_{2}=4, N=3, \\
E_{1}=240, E_{2}=250, E_{3}=260 .
\end{gathered}
$$

Імовірність правильної локалізації Р оцінювалася кількістю правильно локалізованих випадків до загальної кількості випробувань, яке становило 400. Перед порівнянням зображення (електронне та поточне) були центровані та нормувані.

На рис. 1 наведено залежності ймовірності $P$ запропонованого (криві 1) та квадратичного різницевого (криві 2) алгоритмів від контрасту

$$
\Delta T_{12}=T_{2}-T_{1}
$$

для середньоквадратичного відхилення $\sigma=3$ або $\sigma=7$ при фіксованих інших параметрах поточного та еталонного зображень.

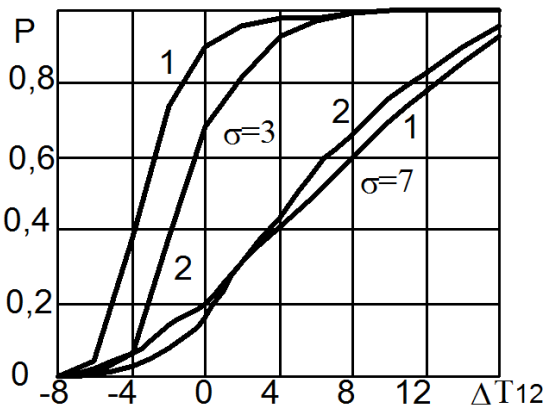

Рис. 1. Залежності ймовірності $P$ запропонованого (криві 1) та квадратичного різницевого (криві 2) алгоритмів від заданого контрасту

При високих рівнях шуму дещо більшою ефективністю володіє звичайний алгоритм, який відрізняється сильною чутливістю до інверсії контрасту, але при малих рівнях шуму запропонований алгоритм істотно перевершує звичайний.

Таким чином, при великих значеннях відношення сигнал-шум запропонований алгоритм істотно перевершує стандартний алгоритм по ймовірності правильного розпізнавання зображення.

\section{Висновки}

У представленому методі на кожному етапі порівняння еталонного зображення з фрагментами поточного зображення запропоновано синтезувати оптимальне числове представлення еталонного зображення, що зберігає відношення порядку на його елементах. Для порівняльної оцінки за ймовірністю правильного розпізнавання об'єкта запропонованого i звичайного квадратичного різницевого алгоритмів були проведені статистичні випробування. При великих значеннях відношення сигнал-шум запропонований алгоритм істотно перевершує стандартний алгоритм по ймовірності правильного розпізнавання зображення.

Напрям подалыших розвідок - прив'язка розробленого алгоритму до існуючих комп'ютерних систем, що використовують еталонні зображення.

\section{СПИСОК ЛІтЕРАТУРИ}

1. Худов В.Г. Аналіз відомих методів сегментування зображень, що отримані з бортових систем оптикоелектронного спостереження / В.Г. Худов, Г.А. Кучук, А.В. Крижний // Системи обробки інформації, 2016. - Вип. 9 (146). - С. 77-80.

2. Kuchuk G., Kovalenko A., Komari I.E., Svyrydov A., Kharchenko V.. Improving big data centers energy efficiency: Traffic based model and method. Studies in Systems, Decision and Control, vol 171. Kharchenko, V., Kondratenko, Y., Kacprzyk, J. (Eds.). Springer Nature Switzerland AG, 2019. Pp. 161-183. DOI: http://doi.org/10.1007/978-3-030-00253-4_ 8

3. Свиридов А. С., Коваленко А. А., Кучук Г. А. Метод перерозподілу пропускної здатності критичної ділянки мережі на основі удосконалення ON/OFF-моделі трафіку. Сучасні інформачійні системи. 2018. Т. 2, № 2. C. 139-144. DOI: https://doi.org/10.20998/2522-9052.2018.2.24

4. Кучук Г.А. Минимизация загрузки каналов святи вычислительной сети / Г.А. Кучук // Системи обробки інформації. - Х.: НАНУ, ПАНМ, ХВУ, 1998. - Вип. 1(5). - С. 149-154.

5. Кучук Г.А. Распределение каналов по трактам узла коммутации при адаптивной маршрутизации / Г.А. Кучук // Вестник НТУ «ХПИ». - Х.: НТУ «ХПИ», 2003. - № 26. - С. $167-172$.

6. Кучук Г. А. Метод параметрического управления передачей данных для модификации транспортных протоколов беспроводных сетей / Г.А. Кучук, А.С. Мохаммад, А.А. Коваленко // Системи обробки інформації. - 2011. - № 8(98). - С. 211-218.

7. Коваленко А.А. Использование временных шкал при аппроксимации длины очередей компьютерных сетей / А.А. Коваленко, Г.А. Кучук, И.В. Рубан // Сучасний стан наукових досліджень та технологій в промисловості. 2018. - № 2 (4). - C. 12-18. - DOI: http://doi.org/10.30837/2522-9818.2018.4.012

8. Коваленко А. А., Кучук Г. А. Методи синтезу інформаційної та технічної структур системи управління об'єктом критичного застосування. Сучасні інформаиійні системи. 2018. Т. 2, № 1. С. 22-27. DOI: https://doi.org/10.20998/2522-9052.2018.1.04. 
9. Donets V., Kuchuk N., Shmatkov S. Development of software of e-learning information system synthesis modeling process. Сучасні інформаційні системи. 2018. Т. 2, № 2. C. 117-121. DOI: https://doi.org/10.20998/2522-9052.2018.2.20

10. Коваленко А. А. Подходы к синтезу информационной структуры системы управления объектом критического применения / А.А. Коваленко // Системи обробки інформації. - 2014. - № 1(117). - С. 180-184.

11. Gomathi B, Karthikeyan N K, Saravana Balaji B, "Epsilon-Fuzzy Dominance Sort Based Composite Discrete Artificial Bee Colony optimization for Multi-Objective Cloud Task Scheduling Problem", International Journal of Business Intelligence and Data Mining, Volume 13, Issue 1-3, 2018, pages 247-266, DOI: https://doi.org/10.1504/IJBIDM.2018.088435

12. Yogesh Awasthi, R P Agarwal, B K Sharma, "Intellectual property right protection of browser based software through watermarking technique", International Journal of Computer Applications, vol. 97, no. 12, 2014, pp. 32-36.

13. Yogesh Awasthi, R P Agarwal, B K Sharma, "Two Phase Watermarking for Security in Database", International Journal of Computing, vol. 4, no. 4, 2014, pp. 821-824

14. Saravana Balaji B, Mohamed Uvaze Ahamed, Eswaran C, Kannan R, "Prediction-based Lossless Image Compression", Lecture Notes in Computational Vision and Biomechanics (Springer), Volume 30, No 1, 2019, pp.1749 - 17961, DOI: https://doi.org/10.1007/978-3-030-00665-5 161

15. Sivaram, M., Porkodi, V., Mohammed, A.S., Manikandan V. Detection of Accurate Facial Detection Using Hybrid Deep Convolutional Recurrent Neural Network. ICTACT Journal on Soft Computing. 2019. Vol. 09, Issue 02. pp. 1844-1850. DOI: 10.21917/ijsc.2019.0256

16. Sivaram, M., Batri, K., Amin Salih, Mohammed and Porkodi V. (2019), "Exploiting the Local Optima in Genetic Algorithm using Tabu Search", Indian Journal of Science and Technology, Volume 12, Issue 1,2019. DOI: 10.17485/ijst/2019/v12i1/139577

17. Amin Salih Mohammed, Saravana Balaji B., Hiwa Abdulkarim Mawlood. Conceptual analysis of Iris Recognition Systems. Advanced Information Systems. 2019. Vol. 3, No. 2. P. 86-90. DOI : https://doi.org/10.20998/2522-9052.2019.2.15

18. Svyrydov, A., Kuchuk, H., Tsiapa, O. (2018), "Improving efficienty of image recognition process: Approach and case study", Proceedings of 2018 IEEE 9th International Conference on Dependable Systems, Services and Technologies, DESSERT 2018, pp. 593-597, DOI: $\mathrm{http} / / / \mathrm{dx}$. doi.org/10.1109/DESSERT.2018.8409201

19. Коваленко А. А. Подходы к синтезу технической структуры компьютерной системы, образующей систему управления объектом критического применения / А.А. Коваленко // Збірник наукових праць Харківського національного університету Повітряних Сил. - 2014. - № 1(38). - С. 116-119.

20. Кучук, Г.А. Метод уменьшения времени передачи данных в беспроводной сети / Г.А. Кучук, А.С. Мохаммад, А.А. Коваленко // Системи управління, навігації та зв’язку. - К.: ЦНДІ НіУ, 2011. - Вип. 3 (19). - С. $209-213$.

21. Yaloveha V., Hlavcheva D., Podorozhniak A. Usage of convolutional neural network for multispectral image processing applied to the problem of detecting fire hazardous forest areas. Сучасні інформаційні системи. 2019. Т. 3, № 1. С. 116120. DOI: https://doi.org/10.20998/2522-9052.2019.1.19

\title{
Рецензент: д-р техн. наук, проф. І. В. Рубан, Харківський національний університет радіоелектроніки, Харків Received (Надійшла) 16.06.2019 Accepted for publication (Прийнята до друку) 24.07.2019
}

\section{Метод формирования эталонного изображения яркого объекта}

\author{
Т. М. Шипова, Г. Н. Зубрицкий, В. В. Кирвас
}

В статье рассмотрены задачи формирования эталонного изображения для объекта, у которого на изображениях возможны существенные изменения яркости. Установлено, что большинство существующих методов при больших значениях отношения сигнал-шум не соответствуют требованиям по вероятности правильного распознавания изображения. Целью статьи является разработка метода формирования эталонного изображения яркого объекта, основанного на выборе его оптимального численного представления, которое в наибольшей степени соответствует текущему изображению. Результаты исследований. В представленном методе на каждом этапе сравнения эталонного изображения с фрагментами текущего изображения предложено синтезировать оптимальное числовое представление эталонного изображения, сохраняет отношение порядка на его элементах. Для сравнительной оценки вероятности правильного распознавания объекта предложенного и обычного квадратичного разностного алгоритмов были проведены статистические испытания. Вывод. При больших значениях отношения сигнал-шум предложенный алгоритм существенно превосходит стандартный алгоритм, по всей вероятности правильного распознавания изображения.

Ключевые сл ов : эталонное изображение, текущее изображение, яркость, критерий максимального правдоподобия, отношение линейного квазипорядка.

\section{The method of forming the reference image of a bright object}

\section{T. Shipova, G. Zubritsky, V. Kirvas}

In article problems of forming of a standard image for an object are considered. At an object on images brightness variations are possible. The majority of the existing methods do not conform to requirements. At great values of a signal-to-noise ratio. On the probability of the correct recognition of the image. The purpose of article is a development of a method of forming of a standard image of a bright object. Which is based on the choice of its optimum numerical representation. What most corresponds to the current image. Results of researches. In the presented method at each stage of comparison of a standard image with fragments of the current image it is offered to synthesize optimum numerical representation of a standard image, saves the order relation on its elements. Statistical tests were carried out. The comparative assessment of probability is carried out. It is studied, the object offered and normal square differential algorithms will how correctly be recognized. Conclusion. At high values of the signal-to-noise ratio, the proposed algorithm significantly exceeds the standard algorithm in the probability of correct image recognition.

Keywords : reference image, current image, brightness, maximum likelihood criterion, linear quasi-order ratio. 